\title{
LA ESCRITURA COMO PALIMPSESTO (UNA FORMA DE LA LOGOFAGIA)*
}

Túa BLESA

Universidad de Zaragoza

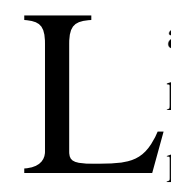

a escritura, y la inscripción en general, vino a superar la naturaleza efímera del habla, ésa por la cual su manifestación es ya propia disolución, tal que, si al principio fue el verbo, en el instante siguiente se esfumó. La escritura, como le explicó Theuth a Thamus, según el relato de Platón en Fedro, «se ha inventado como un fármaco de la memoria y de la sabiduría» (Platón, 1992: 403), esto es, inscripción que permanece, que archiva, argumento al que Thamus dará la vuelta, todo ello en un texto apasionante y que ha dado lugar a comentarios no menos apasionantes.

Ni Theuth ni Thamus, ni Platón, pudieron tener en cuenta el singular modo de escritura que idearía Jorge Luis Borges en "El libro de arena", en cuyas páginas el vendedor de tal libro deja advertido al posible comprador que habría que fijarse con toda atención en lo que leyese, pues lo representado en ellas se desvanecería una vez pasada la página. Escritura, entonces, que es inscripción sin inscripción, sin posibilidad de archivo, escritura que perdura el tiempo de su lectura, efímera, en fin, como lo es el habla y que no habría servido a Theuth como prueba de «fármaco de la memoria y de la sabiduría».

Un modo muy diferente de inscripción es el que atrajo la atención de Sigmund Freud y que le llevó en 1924 a escribir "El «block» maravilloso" ("Notiz über den «Wunderblock»”). Tal artilugio que era entonces novedad, según él mismo dice, se le presentó como analogía extraordinaria del funcionamiento del aparato psíquico tal como lo había concebido el creador del psicoanálisis. Al igual que «el block no ofrece tan sólo una superficie receptora utilizable siempre de nuevo, como la pizarra, sino que conserva

\footnotetext{
* Una versión de este trabajo se presentó por invitación del coordinador, Ángel Escobar, a quien aprovecho la ocasión para expresarle mi agradecimiento, en Palimpsesto: historia cultural y significado literario. Universidad de Zaragoza. Zaragoza, 21-23 de octubre de 2002.
} 
una huella permanente de lo escrito, como la hoja de papel» (Freud, 1924: 2810), así el individuo no conserva fijado todo aquello que experimenta, si bien guarda en el inconsciente huellas, restos de todo ello, restos que además conforman una memoria sin recuerdo aunque sin olvido.

De estos modos de inscripción, el que da a leer la palabra en una única ocasión y el que conserva la huella de lo escrito en algún momento anterior al par que el texto nuevo, el palimpsesto se inclina hacia el segundo modelo, se asemeja a ese block maravilloso en el que una y otra vez las palabras se presentan a la lectura con una tenacidad que va más allá de la escritura que se les superpone. Y se puede añadir que la cultura misma se comporta de esta manera, conservando, lo que hace que el palimpsesto se presente como su sinécdoque. Y, si tal es el funcionamiento del proceso cultural, no de otro modo se comporta la literatura. El texto literario tiene como condición la semejanza, esa cierta forma de repetición, de reiteración, con al menos algunos de los textos literarios anteriores, para lo cual ha de reproducir no pocos de los rasgos constituyentes de aquéllos, ahora hechos también propios. Si ello no se cumpliese, el nuevo texto literario resultaría irreconocible como tal, palabra sin identificar, texto sin género ni ámbito de escritura. En el límite, cabe decir que el texto más literario sería aquél que repitiese uno tras otro todos y cada uno de los componentes de otro texto sancionado ya como literario, tanto es así que en otro lugar propuse que el trabajo de la parodia es el de la literatura misma al exigir esa modalidad textual la presencia de otro $\mathrm{u}$ otros textos ajenos; presencia de otro texto que habrá de darse, como Linda Hutcheon señaló con todo acierto, en la forma de «repetition with difference» (Hutcheon, 1985: 32). Así, la parodia «es la condición de lo literario que ha sido hipertrofiada, la parodia es la oda desmesurada, es la oda atraída hacia el centro, donde se encuentra a ella misma, donde es la oda y su doble» y también que «es lo literario en cursiva» (Blesa, 1994: 58).

La práctica literaria, por otra parte, confirma todo lo anterior, desde la imitatio clásica a lo que Gérard Genette, bien que con presupuestos muy distintos, pudo llamar ya en el título de su libro Palimpsestes. La littérature au second degré (1982), donde describía cuáles y cómo son las relaciones entre unos y otros textos. Si ese libro puede ser sintomático de un cierto pensamiento de lo literario según el cual de esta a aquella página los elementos se trasladan, no lo es menos la teoría de la influencia de Harold Bloom, quien ha llegado a escribir en A Map of Misreading que «there are no texts, but only relationships between texts» (Bloom, 1994: 3; las cursivas en el texto). Y, con presupuestos diferentes, Mijáil Bajtín centraría la cuestión en la multiplicidad de voces. Precisamente en uno de los textos que introdujeron su pensamiento en la teoría occidental, Julia Kristeva escribiría que por la intertextualidad «todo texto se construye como mosaico de citas, todo texto es absorción y transformación de otro texto [...] y el 
lenguaje poético se lee, al menos, como doble» (1974: 1, 190), todo lo cual resulta ser glosa de lo que sucede con la escritura del palimpsesto.

Si en la teoría literaria se ha prestado atención siempre de una u otra forma a la cuestión de los modelos de escritura, es decir, a cómo sobre el nuevo texto se cierne la textualidad anterior y proyecta su sombra sobre él hasta transparentarse en mayor o menor medida en sus trazos, una de las razones ha de ser lo que los propios textos literarios dicen al discurso de la teoría. Y es que no hay duda alguna de que la práctica de la lectura revela muy pronto cómo leer es una cierta forma de releer, cómo el encuentro con la palabra nueva es en mayor o menor grado un reencuentro con algo de lo que otro u otros textos anteriores ya habían dicho. Las formas, los tópicos, las figuras, las estructuras, los personajes, etc. están en un movimiento permanente de regreso desde el pasado, así como en un movimiento de combinación que puede llegar a producir la impresión de novedad.

Si la teoría lo sabe, no lo saben menos, pues, los escritores, desdoblados siempre en teóricos, y ponen en práctica esta sumisión del trazo a lo antes trazado, bien se ponga de manifiesto, bien quede más o menos encubierto, bien se lo propongan en sus presupuestos, bien se imaginen a sí mismos cubiertos por la pantalla de la originalidad. A propósito de este escribir en cuanto reescribir, uno de los casos más sobresalientes, si no el más, es el de "Las intrigas venecianas o el síndrome Myslowitz-Braunschweig" de Ignacio Prat, relato que, como señalé en otra ocasión, está compuesto por una primera mitad tomada de «Intrigas venecianas o Fray Gregorio de Jerusalén» de José María Blanco White y cuando se interrumpe la copia de este texto se pasa a tomar prestado el resto de "Myslowitz-Braunschweig-Marsella", uno de los escritos de la colección denominada "Haschisch" de Walter Benjamin. En tal modo de composición Prat escribió tan sólo unas pocas palabras, con lo que no parece impropio hablar de una escritura sin escritura o, si se prefiere, de una doble escritura (véase Blesa, 2008). Hasta donde yo sé, nadie se atrevió a tanto ${ }^{1}$. O sí. José-Miguel Ullán en Mortaja redactó una serie de poemas que no sólo tienen la apariencia de crónicas de sucesos de la prensa, sino que en efecto lo son y con muy ligeros y escasos retoques (véase Blesa, en prensa). Teniendo en cuenta estos casos y algunos de los que se citan a continuación, ¿no debería hablarse de un rasgo de lo que fue lo novísimo en la poesía española que consistiría en la práctica de copia?, ¿de un escarnio de la idea de creación?

$\mathrm{Si}$ "palimpsesto" en el trabajo antes citado de Genette es una metáfora, y hay que decir que afortunada, no lo es menos en, por ejemplo, este poema de Leopoldo María Panero de su libro Teoría del miedo:

\footnotetext{
${ }^{1}$ La obra literaria de Ignacio Prat es toda una trama de apropiaciones; véase, además del trabajo aludido donde se dan las precisiones pertinentes, Blesa 1990. Puede leerse el relato en cuestión en Prat (1983: 131-137).
} 


\title{
PALIMPSESTO
}

\author{
"Er resplan la flors enversa" \\ lo dijo Raimbaut d'Aurenga \\ convirtiendo andrajos en silbos \\ y silbándole al diablo: "Tiger burning in the night" \\ qué inmortal mano o qué ojo pudo crear tu aterradora simetría \\ lo dijo Blake mientras sus pies ardían \\ en el fuego secreto de la nada donde habitan \\ insectos y pulgones más viciosos que la vida \\ Oh tigre, tigre ardiendo fuerte \\ nos rescata de la vida.
}

(Panero 2001: 60).

El título del poema afirma que se trata de un palimpsesto, sin embargo lo es tan sólo en un cierto sentido, digamos que sub specie figurae. Evidentemente, incorpora hasta dos citas de textos anteriores, de los que se respeta su lengua -aunque una de ellas no es literal, como señalo enseguida-, con sus correspondientes comillas e incluso se deja constancia en el poema mismo de los autores de los que se toman. Así, por esa supervivencia de escrituras anteriores, no es ilegítimo decir de "Palimpsesto" que sea título inapropiado. Hay que añadir que este poema reescribe más de lo que en él se marca. Si el verso inicial se corresponde con el primero de una de las composiciones de Raimbaut d'Aurenga, tal como se advierte, el «convirtiendo» que se lee a continuación proviene también del léxico de la transformación que va pautando el texto provenzal: «enversa» (vv. 1, 17 y 33), «enverse» (vv. 9, 25 y 41) -por ejemplo, «flors enversa» lo traduce Martín de Riquer en Los trovadores como «flor inversa», a lo que agrega en nota «fflor inversa, invertida, contraria', es decir: lo contrario de la flor» (de Riquer 1975: 445 y n. 1)-. Del mismo modo, en dicha composición se lee «siscle(s)" (vv. 5, 13, 21, 29, 37 y 45), que es el origen de «silbos» (v. 3) en el poema de Panero quien se muestra entonces a momentos como traductor. Por su parte, «Tiger burning in the night» es cita inexacta, o resumida, de «Tyger! Tyger burning bright / In the forests of the night», versos iniciales (se repiten también en la última estrofa) de "The Tyger", en Songs of Innocence and Experience de William Blake (Blake, 1975: 60-61), poema que es también el origen del verso 9 de "Palimpsesto", «Oh tigre, tigre ardiendo fuerte», donde «fuerte» habrá de ser leído como traducción de «bright»². Y continúa "Palimpsesto": «qué inmortal mano o qué ojo pudo crear tu aterradora simetría», lo que es simple traducción de los versos de Blake que suceden a los ya citados: «What immortal hand or eye / Could frame thy fearful symmetry!» y aún se puede señalar que «fuego» (v. 7) se corresponde con «fire» (v. 6). Teniendo todo esto en cuenta, este "Palimpsesto" lo es porque su título así lo dice, pero además porque permite leer en él

\footnotetext{
2 Además de que en no pocas de sus composiciones Panero traduce, son singulares sus traducciones, recogidas en Cuentos completos (Panero 2007) y en Traducciones. Perversiones (Panero 2011), tarea a la que me he referido en mis introducciones a ambos volúmenes.
} 
fragmentos, inscritos en diversas formas, de textos anteriores, procedimiento tan típico de la literatura y de extraordinaria frecuencia en la literatura moderna, del que José Enrique Martínez ha ofrecido unos detallados panorama y catálogo en su La intertextualidad literaria (Martínez, 2001).

Si bien se da, pues, una utilización retórica del término palimpsesto, es también cierto, y sin duda es lo que ahora resulta más relevante, que la escritura literaria sí manifiesta en ocasiones que el modelo del palimpsesto, la producción de palimpsestos, no es algo que pertenece al pasado, sino que está todavía vigente y se pueden leer algunos textos conviviendo en un soporte único, por lo que se debe hablar de palimpsesto en su sentido más recto.

Y así, en su sentido recto, es como ha de hablarse de palimpsesto ante el caso del poema del libro De lo real y su análisis (1994) de Jesús Munárriz de idéntico título que el anterior y que presento a continuación, aunque de idéntico título por el trabajo que le es propio al palimpsesto:

\section{Insomio \\ (Palimpsesto)}

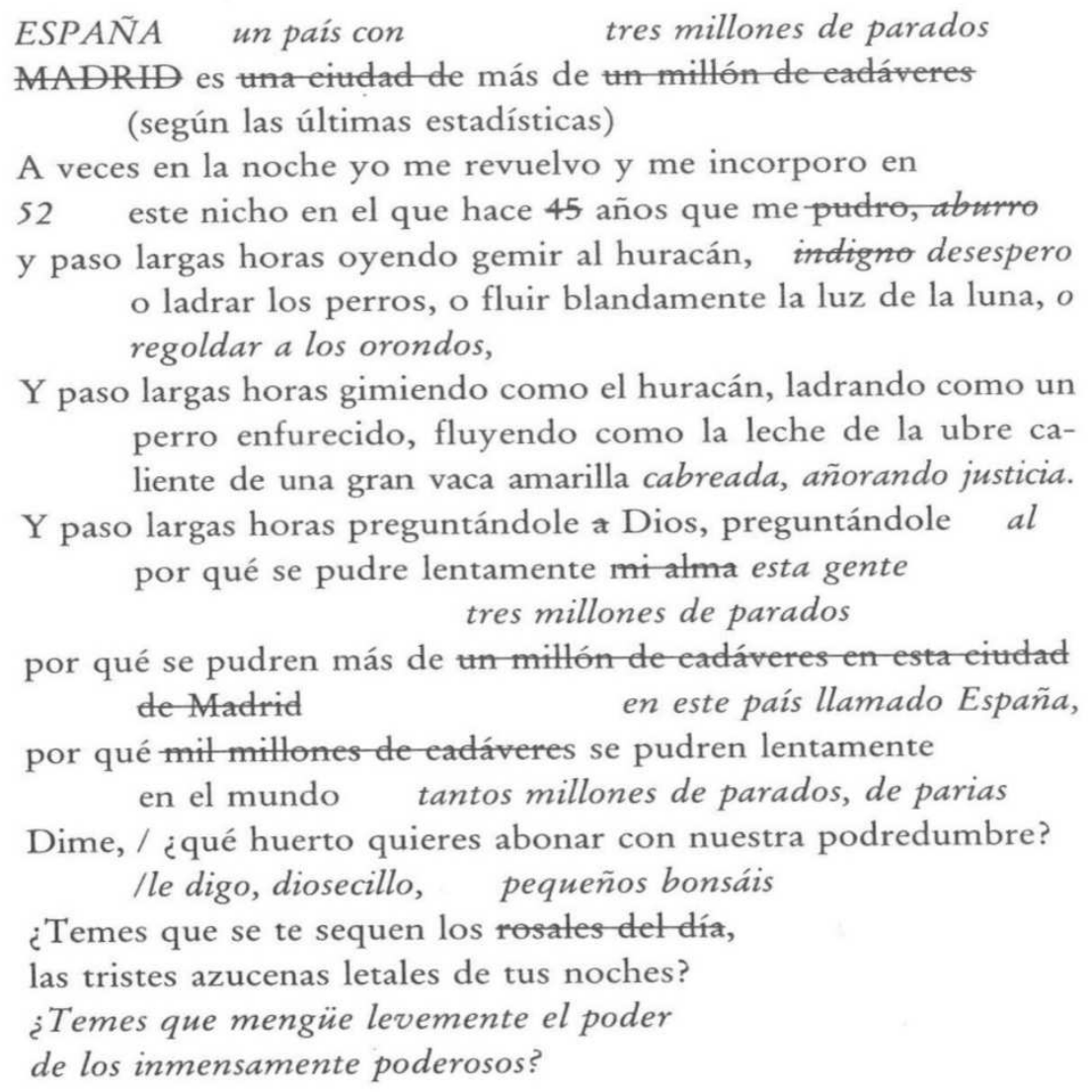
perro enfurecido, fluyendo como la leche de la ubre caliente de una gran vaca amarilla cabreada, añorando justicia. 
El procedimiento de composición que ha seguido Munárriz en este texto es bien evidente. Tomando a modo de hoja en blanco una página ya recorrida por el trazo, el muy conocido poema de Dámaso Alonso "Insomnio", de su Hijos de la ira (1944), esto es, un poema ya escrito, la "creación" pasa aquí como labor preparatoria o primer ejercicio por el borrado de todo aquello que en la actual situación de escritura resulta inactual, inapropiado para el escritor en cualquiera de sus sentidos por las razones que sean. Así, "Insomnio" viene a ejercer la función del borrador, a partir del cual se lleva a cabo la redacción definitiva, aunque ésta coexiste con tal "borrador", ofreciendo la posibilidad de una lectura que es, al menos, doble. $Y$ es que el poema no destina a la papelera o reserva para el archivo personal el "borrador", sino que lo recalifica como texto, latente si se quiere, al darlo a la lectura.

Algunos de los cambios en este paso del proceso de génesis de "Palimpsesto" merecen cierta atención. Si hacia principios de la década de los cuarenta Madrid era «una ciudad de más de un millón de cadáveres» (v. 1), cincuenta años después la voz poética no se referirá ya a Madrid sino a España y la población de la que se habla no podrá ser ya la de los habitantes muertos vivientes de tal ciudad sino otra, la «de más de tres millones de parados» modificando con este gesto de supresión y adición textual la significación del discurso, gesto que exige más adelante el tachado de «un millón de cadáveres en esta ciudad de Madrid» (v. 6) para leerse ahora en los interlineados «tres millones de parados» y «en este país llamado España». Obviamente, tanto «cadáveres» como «parados» son denominaciones dictadas por una mirada crítica a la realidad. En otro pasaje, en aquel en el que Dámaso Alonso había dejado constancia de su edad al escribir el poema donde se leía - iy todavía se lee!, advertencia que vale para todos los casos- «hace 45 años que me pudro» (v. 3), se debe leer ahora atendiendo a los trazos en los espacios que las palabras dejan en blanco «hace 52 años que me desespero» -el año de nacimiento de Munárriz es 1940, lo que fecha la redacción, por así decir, del poema en 1992-, solución que se alcanza tras haber asistido a la sustitución de «pudro» por «aburro» primero y, desechado este verbo, por «indigno» más tarde, a su vez reemplazado en un momento posterior, cadena de sustituciones que se ofrece toda ella a la vista, con lo que el texto publicado exhibe todos los estadios del proceso genético de su escritura. O sea el caso, en fin, de la imagen vegetal de «los grandes rosales del día» (v. 9), a la que se le superpone en el nuevo poema «pequeños bonsáis», como un ejemplo más de que la escritura de "Palimpsesto" supone la puesta al día del poema que cuenta ya con medio siglo de existencia.

En todos estos pasos del discurso por lo demás lo que tiene lugar es la doble operación de supresión y adición. Sin embargo, en otros casos la transformación es por simple agregación: así, la marca tras «Dime» (v. 8) indica que el lector habrá de insertar en tal lugar «le digo, diosecillo»; y si "Insomnio" discurre por un total de diez versos o 
versículos, "Palimpsesto" no se detiene ahí, sino que, tomando como modelo los versos inmediatamente anteriores, los vv. 9 y 10, adjunta otros dos más al texto. Por lo demás, como es bien evidente, la mirada a un mundo degradado de Alonso se continúa o incluso se puede decir que se intensifica en la nueva redacción, corregida, del texto.

"Palimpsesto" de Munárriz muestra, pues, con toda evidencia cómo en ocasiones la palabra nueva va a encontrar su lugar en los espacios que le permite, aunque sea tras su tachado, el texto anterior, escritura, entonces, que no ocupa el lugar que le es propio, el del cuerpo del texto, sino que se desplaza al interlineado, al margen -en cualquier caso el lugar que no es la línea, el centro-, desde donde se superpone a la preexistente, pero sucede, sin embargo, que la palabra nueva no culmina su tarea, no termina de borrar a aquélla, sino que la conserva haciéndola manifiesta, de manera que la lectura permite, aunque más bien ha de decirse que obliga a ello, la lectura de dos textos dispuestos sobre un soporte único, dos textos en un único texto, que se lee efectivamente, al menos, como doble. No es detalle menor, por lo demás, el hecho de que, en ejemplos como éste y hablando en términos de cantidad de discurso, el anterior, el "tachado", resulta ser notablemente mayor que la palabra añadida -lo propiamente escrito por Munárriz es más bien poco-, aunque el resultado es que, dado que el discurso antiguo no se desvanece, el final resultante, que incluye necesariamente a éste, será sistemáticamente de mayor extensión. Y, aunque es verdad que Munárriz ha escrito, como ya he indicado, poco, hay que añadir que ha (re)escrito todo el conjunto y el gesto de la firma de la palabra ajena, doblemente firmada, y de la propia, que firma lo propio y lo apropiado, zanja la cuestión.

Por otra parte, el poema de Munárriz es una realización particular del tipo textual al que en otra ocasión di el nombre de tachón en la exposición de la escritura logofágica (Blesa, 1998: 63-87), en este caso concreto en su modalidad de simulacro de tachadura, de tachón-no-tachón, puesto que, si bien representa la tachadura, la pone en escena, mantiene legibles, a pesar de ello, los pasajes tachados. Y no sólo es muestra del mencionado tipo, sino que por su condición de doble texto, "Palimpsesto" de Munárriz responde también al tipo ápside, ése que requiere dos textos que se exigen mutuamente (Blesa, 1998: 89-148), doble enunciado que reclama además una estructura de doble enunciación.

Este "Palimpsesto" se presenta, en definitiva, como un verdadero palimpsesto, texto en el que de manera más o menos espectral se acaba poniendo de manifiesto algún pasaje de un texto anterior -más bien muchos en este ejemplo concreto-. Claro que inmediatamente hay que añadir que las circunstancias que han llevado a este tipo textual logofágico, a este tipo de palimpsesto moderno, han debido ser muy diferentes de aquellas otras que determinaron la producción de los verdaderos palimpsestos. No se 
puede pensar ahora en una situación de carestía o escasez del soporte de la escritura, sino en un hecho muy diferente como es el que la escritura en su búsqueda ansiosa de novedades -y convendrá recordar que un poema como "Palimpsesto" debe leerse como producto de una relectura de la vanguardia- resulta que vuelve una y otra vez sobre la propia tradición para encontrar allí el modelo desde el cual será posible continuar su iterancia por medio precisamente de la reiteración.

Consideremos ahora otro ejemplo, el de este poema de Guido Savio.

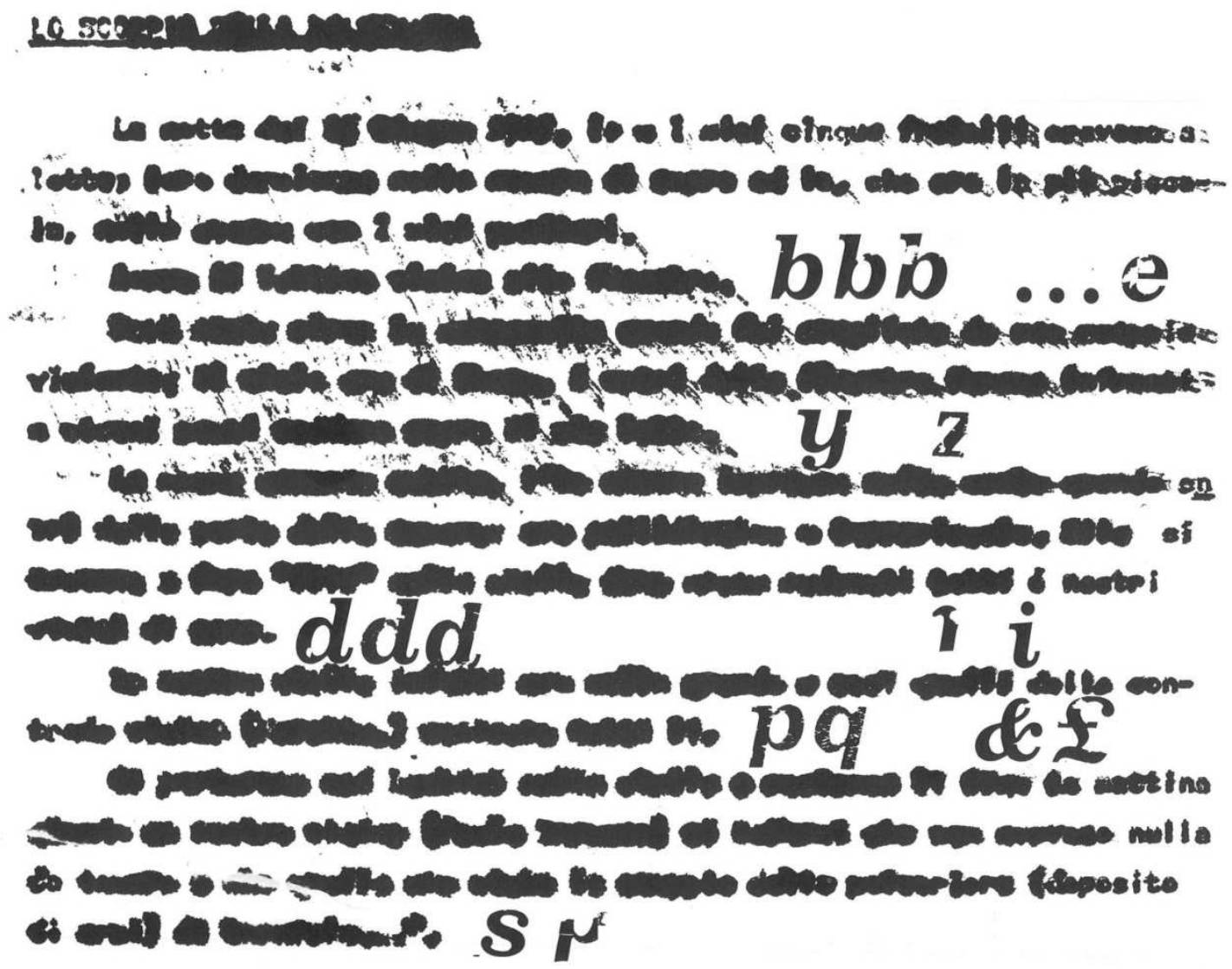

(Savio, 1982: 194)

Se diría que el soporte de la escritura ha sufrido alguna de las no pocas calamidades que los papiros, etc. de la antiguiedad hubieron de atravesar antes de llegar a las manos de un lector moderno. Como consecuencia de ello, la escritura ha difuminado sus trazos, la tinta se ha corrido, emborronado y lo que era el dibujo de las letras ha pasado a ser una simple sucesión de manchas, de las que muy pocas admiten la lectura y aun ni siquiera la conjetura. Texto, entonces, el que ahora se considera, que no pasa de ser una pura presunción de texto, escritura a la que le conviene mejor la denominación de representación de escritura, escritura ante la que la lectura se detiene, entra en una crisis sin solución posible -a no ser la de la aplicación de los modernos procedimientos de lectura de textos antiguos que la técnica ha aportado- y finalmente 
no llega a tener lugar. Así, este texto presenta el caso de la escritura sin posibilidad de lectura alguna, lo que convierte al poema de Savio en ejemplo relevante de algunas perspectivas contemporáneas a propósito de la imposibilidad de la interpretación de los textos, de la ausencia del sentido de la escritura.

Además de todo lo anterior, este poema de Savio nos muestra su carácter de auténtico y verdadero palimpsesto. Aprovechando una vez más los blancos que un texto anterior deja en el soporte, otro texto se ha introducido en tales huecos y se muestra legible, texto éste, que en este caso resulta ser nada más que unas pocas letras, bien legibles sí, pero que no terminan de configurar ni siquiera una palabra reconocible por el lector, de manera que lo legible resulta estar tan privado de lectura como lo estaba lo ilegible, con lo que este texto y aquellos otros que se le asemejan insisten en la idea de la lectura como operación condenada siempre al fracaso, a la que acabo de aludir. Por lo demás, este poema impone otra vez la afiliación vanguardista, esa aventura entendida como marginal o, peor, banal por tantos y tan equivocadamente.

Un último poema, ahora de Jenaro Talens, de El cuerpo fragmentario (1978), mostrará la vigencia del modelo del palimpsesto, así como de las diversas formas de manifestación, en al menos parte de la escritura más actual:

\section{P R O S A}

La relación entre la universalidad y la particulariLa determinación de la lectura sobre la escritura dad de la contradicción es una relación entre el de un texto poético es la determinación del inconscarácter común y el carácter individual de las ciente común sobre el inconsciente individual del contradicciones. Por carácter común entendemos el texto poético. Por inconsciente común habría que

(Talens, 1989: 197-199)

Como resulta evidente al llegar a la segunda línea, "Prosa" es un texto en el que se leen dos textos que se reparten el espacio de la página de tal manera que uno discurre por los interlineados que el anterior le ofrece como blanco. Dejando ahora para otra ocasión las relaciones que entre uno y otro discurso pudieran establecerse, lo que aquí interesa es esta convivencia de la palabra doble. Como el propio autor ha explicado, el texto en redonda es una mera transcripción de Acerca de la práctica de Mao Ze Dong -antes Mao Tse Tung- y las líneas en cursiva la escritura propia -así lo explica el poeta en Negociaciones para una poética dialógica, (Talens, 2002: 87); por un lapsus en tal lugar se dice «cursivas» por «redondas»- y una y otra discurren armoniosamente a la 
vez que nunca la una irrumpe en la otra, tal como paralelas, si bien la una presupone continuamente a la otra y ofrecen en último término una imagen textual que pone en evidencia cómo todo texto es, de una u otra manera, función de otro u otros textos, cómo un texto exige siempre como su condición necesaria la copresencia de otros, si bien, ya sea por comodidad, ya por un descuido que se da generalizado en casi todo acto de lectura real, esos otros textos no se tienen en consideración, casi como si no existiesen, y en general la lectura tiene lugar en un estado de ficción que da por hecho lo que precisamente no es así ni podría serlo, el texto como unidad única, independiente, autónoma con respecto a la textualidad en general, lo que, y nuestros ejemplos nos lo advierten con rotundidad, no es posible mantener.

Si bien hoy se dan usos del término palimpsesto en sentido traslaticio y en sentido recto, según testimonian los apuntados o reproducidos anteriormente, se puede añadir que en ocasiones se utiliza palimpsesto -y no podrá ser lo de menos este uso o incluso abuso, aunque ¿cómo dudar de su legitimidad?, del término- también para referirse a cierto tipo de traducciones, como sucede en los poemas de la sección "Palimpsestos para una llama" de Viaje al fin del invierno de Jenaro Talens -véase también al respecto Negociaciones (Talens, 2002: 136-137)-, lo que está señalando a cómo la traducción es un tipo de escritura que surge de la posibilidad de la doble textualidad y la pone en texto.

Es el caso que resulta claro que, a la vista de los ejemplos presentados, que son sólo un síntoma de unas ciertas formas de escritura de las que se podrían aportar no pocos otros casos, se puede afirmar que el tipo de texto llamado palimpsesto no es algo que pertenece al pasado, sino que continúa siendo plenamente actual. Es más, habrá que decir que no se trata tan sólo de que se puedan recoger algunas ocurrencias de palimpsesto en la escritura contemporánea, sino que son precisamente éstas, entre otras, las que más preguntas presentan en la lectura -sobre la escritura, sobre la significación, sobre el lenguaje- $y$, por tanto, que es éste un tipo de escritura de los que implican hoy un mayor interés.

Los ejemplos aquí recogidos, por otra parte, siendo todos ellos palimpsestos legítimos, no ofrecen una absoluta uniformidad, sino que se dan entre ellos unas ciertas diferencias, todo lo cual parece estar exigiendo a la teoría literaria una reflexión, aquí tan sólo esbozada, así como una tipología de las diversas formas que se presentan y que a la vista de los textos reproducidos parece que habrían de integrarse en la teoría general de la logofagia.

Entre otras cuestiones que esta textualidad plantea está la ya reiterada idea de que es imposible, salvo que se prefiera instalarse en una situación claramente falsa, pensar en los textos como si fuesen entidades desligadas de la textualidad general y cada uno 
de los textos de series de otros textos. El palimpsesto en su vigencia actual declara que el discurso no es ajeno en modo alguno a la discursividad y a una diversidad de discursos concretos. Los palimpsestos contemporáneos son una exhibición de la interrelación de unos textos con otros, de la dependencia mutua, de que todo texto es tan sólo un punto en una red inmensa, inabarcable en último término, de palabras. Todo ello, como puede suponerse, tiene inmediatas y no leves consecuencias sobre la lectura de los textos.

Desde otro punto de vista, los textos palimpsestos como los aquí considerados ponen en cuestión la noción misma de sujeto, del sujeto que ha de tenerse por responsable del texto. $\mathrm{Y}$ es que en su doble, o múltiple textualidad, el palimpsesto interroga sobre la cuestión de la firma, que será ahora ya no una, sino una doble, o múltiple, firma, que remite a un sujeto que no se deja contener ya en una sólida unidad, sino que, a modo del sujeto lacaniano, se ha hecho a sí mismo desde el otro, siendo, por tanto, un yo que es un otro hecho propio. Una firma, entonces, que será mucho más marcadamente ilegible que lo es toda firma. A este respecto de la doble firma, regresa la cuestión de la traducción, en particular en aquellas ocasiones en que el traductor no acepta que su tarea sea subsidiaria, sino una especialización de la de escritor, situación en la que destaca el quehacer del traductor Leopoldo María Panero, tanto cuando trabaja con relatos como cuando lo pervertido son poemas -véanse las referencias de la n. 2-.

Y está por fin la cuestión de cómo leer un palimpsesto actual. El discurso, bifurcado ahora en dos, pero quizá en muchos discursos, ¿cómo podrá producir algún efecto de sentido que resultase estable? La palabra, permanentemente puesta en roce con otra u otras palabras, habrá de dar como resultado la diseminación de la significación hasta hacer que sea una tarea imposible la labor de recogida. Y lo anterior queda dicho considerando tan sólo los textos que el palimpsesto hace presentes. Pero, si por sinécdoque el palimpsesto lo que está proclamando es cómo su condición de pluralidad textual es la condición de todos los textos aun cuando no se configuren como palimpsestos, cada uno de los cuales está invocando en cada uno de sus pasos otros textos, entonces la invocación del texto, o textos presentes, a los otros ausentes cobra unas dimensiones absolutamente inconmensurables, de tal modo que el sentido se habría de construir bajo la imagen del palimpsesto mismo, el sentido como circulaciones de sentidos, como lugar de cruce de la iterancia general de los signos.

\section{Referencias bibliográficas}

BLAKE, W. (1975): A Choice of Blake's Verse, sel. e intr. Kathleen Raine, Londres, Faber and Faber. 


\section{La escritura como palimpsesto (una forma de la logofagia)}

BLESA, T. (1990): Scriptor ludens. Ensayo sobre la poesía de Ignacio Prat, Zaragoza, Lola Editorial.

(1994): "Parodia: Literatura", en La parodia. El viaje imaginario. Actas del IX

Simposio de la Sociedad Española de Literatura General y Comparada, Zaragoza, Universidad de Zaragoza/Banco Zaragozano, t. II, pp. 57-64.

- (1998): Logofagias. Los trazos del silencio, Zaragoza, Trópica-Anexos de Tropelías.

(2008): "Escritura sin escritura: doble escritura", Revista Jinzo de humanidades, III, 6-7, primavera-verano, pp. 39-45.

_ (en prensa): "La palabra apropiada: José-Miguel Ullán”, Mira por quién JoséMiguel Ullán, Valencia, Pre-Textos.

BLOOM, H. (1994): A Map of Misreading, Nueva York, Oxford University Press.

BORGES, J. L. (1975): "El libro de arena”, en El libro de arena, Madrid, Alianza, pp. 95-99.

DE RIQUER, M. (1975): Los trovadores. Historia literaria y textos, Barcelona, Planeta. FREUD, S. (1974): “El «block» maravilloso", en Obras completas, trad. Luis LópezBallesteros, Madrid, Biblioteca Nueva, t. VII, pp. 2808-2811.

HUTCHEON, L. (1985): A Theory of Parody. The Teachings of Twentieth-Century Art Forms, Nueva York y Londres, Methuen.

KRISTEVA, J. (1974): “La palabra, el diálogo y la novela”, en Semiótica, 1, trad. José Martín Arancibia, Madrid, Fundamentos, pp.187-225.

MARTÍNEZ FERNÁNDEZ, J. E. (2001): La intertextualidad literaria, Madrid, Cátedra.

MUNÁRRIZ, J. (1994): De lo real y su análisis, Madrid, Hiperión.

PANERO, L. M. (2001): Teoría del miedo, pról. L. M. P., epíl. Túa Blesa, Tarragona, Igitur, $2^{\mathrm{a}}$ ed. aumentada.

(2007): Cuentos completos, ed. y pról. Túa Blesa, Madrid, Páginas de Espuma. (2011): Traducciones. Perversiones, ed. y pról. Túa Blesa, Madrid, Visor.

PRAT, I. (1983): Para ti. 1963-1981, ed. José Luis Jover, Valencia, Pre-Textos.

SAVIO, G. (1982): “[Título ilegible]”, $\operatorname{Doc}(k) s$, 50, otoño, p. 194.

TALENS, J. (1978): El cuerpo fragmentario, en Cenizas de sentido, Madrid, Cátedra, 1989.

(1997): Viaje al fin del invierno, Madrid, Visor.

(2002): Negociaciones para una poética dialógica, ed. Susana Díaz. Madrid,

Biblioteca Nueva. 